\title{
Vaccination against human papillomavirus in Switzerland: simulation of the impact on infection rates
}

\author{
André Berchtold • Pierre-André Michaud • \\ Denise Nardelli-Haefliger · Joan-Carles Surís
}

Received: 29 May 2008/Revised: 31 March 2009/Accepted: 11 September 2009/Published online: 1 October 2009

(c) Birkhäuser Verlag, Basel/Switzerland 2009

\begin{abstract}
Objectives Human papillomavirus (HPV) is a sexually transmitted infection of particular interest because of its high prevalence rate and strong causal association with cervical cancer. Two prophylactic vaccines have been developed and different countries have made or will soon make recommendations for the vaccination of girls. Even if there is a consensus to recommend a vaccination before the beginning of sexual activity, there are, however, large discrepancies between countries concerning the perceived usefulness of a catch-up procedure and of boosters. The main objective of this article is to simulate the impact on different vaccination policies upon the mid- and long-term HPV 16/18 age-specific infection rates.

Methods We developed an epidemiological model based on the susceptible-infective-recovered approach using Swiss data. The mid- and long-term impact of different vaccination scenarios was then compared.
\end{abstract}

\footnotetext{
A. Berchtold · P.-A. Michaud · J.-C. Surís

Groupe de Recherche sur la Santé des Adolescents (GRSA),

University Hospital Center and University of Lausanne,

Lausanne, Switzerland
}

P.-A. Michaud · J.-C. Surís

Unité Multidisciplinaire Pour la Santé des Adolescents (UMSA),

University Hospital Center and University of Lausanne,

Lausanne, Switzerland

D. Nardelli-Haefliger

Institut de Microbiologie, University Hospital Center

and University of Lausanne, Lausanne, Switzerland

\author{
A. Berchtold ( $\square)$ \\ Institut de Mathématiques Appliqués (IMA), \\ University of Lausanne, SSP, Anthropole, \\ Lausanne 1015, Switzerland \\ e-mail: andre.berchtold@unil.ch
}

Results The generalization of a catch-up procedure is always beneficial, whatever its extent. Moreover, pending on the length of the protection offered by the vaccine, boosters will also be very useful.

Conclusions To be really effective, a vaccination campaign against HPV infection should at least include a catchup to early reach a drop in HPV $16 / 18$ prevalence, and maybe boosters. Otherwise, the protection insured for women in their 20s could be lower than expected, resulting in higher risks to later develop cervical cancer.

Keywords Human papillomavirus - Vaccination .

Catch-up · Booster · Epidemiological model · SIR model

\section{Introduction}

Human papillomavirus (HPV) is a sexually transmitted virus of particular interest, because of its high prevalence rate, and because of the causal association of the high risk (HR) HPV types, most often types 16 and 18, with cervical cancer (Bosch et al. 2002; Brown et al. 2005; IARC Monograph Working Group 2007). HPV infection is very common in sexually active adolescents and young adults (Dunne and Markowitz 2006; Wiley and Masongsong 2006), and the acquisition of HPV occurs soon after sexual debut (Brown et al. 2005; Centers for Disease Control and Prevention 2007) as sexual intercourse is the primary route of genital HPV infection (Burchell et al. 2006). More than 100 different HPV types have been identified, the most problematic ones being types 16 and 18 . Women under age 25 years have the highest acquisition of HR HPV types per year (Bosch and Harper 2006). Swiss data based on a small clinical sample $(N=134)$ of adolescents aged $14-20$ years show a prevalence of $14.2 \%$ for HR HPV type (Lüdicke 
et al. 2001). A US-based study among women aged 1825 years showed an overall prevalence of $27 \%$ that declined with age (Manhart et al. 2006). In the United Kingdom, HPV prevalence rates decline from $19 \%$ for those under age 25 to less than 3\% for those aged 40 and above (Peto et al. 2004).

Much attention has been recently ported to HPV, since two prophylactic vaccines (Cervarix and Gardasil) have proven to be well-tolerated, highly immunogenic, and effective in preventing type specific cervical HPV infection and associated intraepithelial neoplasia (Lowy and Schiller 2006). Both vaccines prevent HPV16 and 18 infections when three intramuscular doses are administered over 6 months to young adults. It must be noted that since all trials were performed among women aged 18 and over, protection in younger girls is only an extrapolation. Even if there is a consensus to recommend a vaccination before the beginning of sexual activity, there are, however, large discrepancies between countries with respect to the target ages for basic and catch-up vaccination. The need for boosters will also rely on the results of still ongoing phase III and IV trials. The purpose of this article is then to explore and compare different vaccination scenarios.

Sexual behavior is the most constant predictor of acquiring HPV infection (Centers for Disease Control and Prevention 2007). Although many risk factors have been described in the literature, number of sexual partners (Lüdicke et al. 2001; Moscicki et al. 2001; Tarkowski et al. 2004; Dunne and Markowitz 2006; Manhart et al. 2006; Dunne et al. 2007), together with having had a new sex partner (Giuliano et al. 2002; Winer et al. 2003; Dunne and Markowitz 2006; Dunne et al. 2007) are the most consistent. Other factors such as younger age (Ho et al. 1998; Dunne and Markowitz 2006; Manhart et al. 2006; Dunne et al. 2007), early age at first intercourse (Kahn et al. 2002; Manhart et al. 2006), or substance use have also been described as risk factors, but other studies found no association with them (Ho et al. 1998; Kjaer et al. 2001; Lüdicke et al. 2001; Kahn et al. 2002; Sellors et al. 2003; Winer et al. 2003; Tarkowski et al. 2004; Burchell et al. 2006; Manhart et al. 2006). The characteristics of the sexual partner's behavior are also important. It has been described that partner's promiscuity (defined as number of sexual partners) is the most important risk factor (Ho et al. 1998; Kahn et al. 2002; Winer et al. 2003; Dunne and Markowitz 2006; Winer et al. 2006).

HPV transmission is directly linked to the sexual behavior of adolescents and young adults. In Switzerland, median age at first intercourse is 18.5 years both for males and females, and the proportion of those having had sexual intercourse before age 15 is $6.8 \%$ for males and $3.4 \%$ for females (Wellings et al. 2006). The rate of sexual activity (intercourse) among Swiss youth ranges from $13 \%$ of males and $7 \%$ of females at age 14 to $80 \%$ for both genders at age 20 (Kuendig et al. 2003; Narring et al. 2004). Swiss data also indicate that $36.6 \%$ of males aged $17-20$ had one partner in the previous year, $18 \%$ two, and $12 \%$ three or more. The percentages for females in the same age group were, respectively, 48, 10, and 5\%. For males aged 2130 years, $63 \%$ had one partner in the previous year, $10 \%$ two and $14 \%$ three or more. For females in this age group, the percentages were 85,5 , and $4 \%$. Finally, $85 \%$ of males aged 31-45 had one partner in the previous year, 5\% two and $6 \%$ three, while for females the figures were 89,3 , and 1\% (Balthasar et al. 2003).

As for any new vaccine, the duration of the vaccine's protection is yet undefined (Centers for Disease Control and Prevention 2007), but results available to date only demonstrate a sustained efficacy up to $4.5 / 6$ years (Dunne and Markowitz 2006; Ault 2007; Centers for Disease Control and Prevention 2007). Consequently, the potential need for a booster is a research area of greatest importance (Bosch and Harper 2006). Moreover, if a booster is required, focusing vaccination programs on 12-year-olds may be more cost-effective than focusing on infants (Taira et al. 2004).

It has also been debated whether males should be vaccinated. Although some authors (Hugues et al. 2002) report that vaccinating both men and women would result in a higher decrease in HPV prevalence, modeling evidence to date indicates that vaccinating both genders would have little benefit over vaccinating females only (Barnabas et al. 2006).

This article follows from a request made by the Swiss Commission for Vaccination to perform a modeling of the impact of a vaccine upon the infection rate by HR HPV types among Swiss females. Here, we compare the midand long-term efficacy of the different combinations of catch-up and/or boosters on the basis of an epidemiological model of the HPV infection prevalence estimated from Swiss data. In all cases, the routine vaccination program would start at age 12 .

\section{Methods}

Our model of HPV virus diffusion is derived from the classic susceptible-infective-recovered (SIR) model introduced first by Kermack and McKendrick (1927) and then broadly used in epidemiology (Anderson 1982; Daley and Gani 2001). A similar, but less complete, HPV model was proposed by Corley (2006); other approaches are due to French et al. (2007) and Insinga et al. (2007). SIR models describe year after year a cohort of individuals mimicking a real population. Individuals in the model are classified as either susceptible of being infected (state S), 
infective (state I), or recovered (state R). Two additional states, V for vaccinated and VI for vaccinated-infective are also considered to take into account the effect of a vaccination program. State $\mathrm{V}$ groups individuals that are immune after having received the vaccine. State VI groups individuals having received the vaccine when already infected. For the purpose of clarity, the rare individuals belonging to this last state are aggregated with infective when presenting the results. The model considers individuals of both genders, but only results for females are reported.

The level of sexual activity depends on the individuals and must be taken into account into the modeling. For that purpose, the population was divided into several mutually exclusive sexual profiles corresponding to different groups of sexual activity. The repartition among groups was specific for each class of age. Each group is defined by the average number of different partnerships formed each year. The core of any model for sexually transmitted viruses is a process of sexual mixing between individuals (Aral et al. 1999). This process manages all sexual contacts made between individuals, hence all possibilities of virus transmission. The process of sexual mixing used in this model is derived from the one proposed by Garnett (2002). On the contrary of the solution adopted in previous models, the process implemented here takes explicitly into account the fact that partnerships between individuals of different ages are very frequent.

The model works in discrete time, each period being 1 year. The transitions from any state of the model $(\mathrm{S}, \mathrm{I}$, $\mathrm{R}, \mathrm{V}$, and VI) to any other state are modeled through a set of difference equations. Figure 1 shows the possible (a)

(V)

(VI)

Before vaccination

(c)

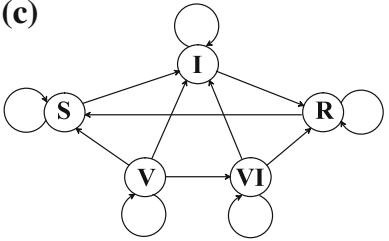

After vaccination

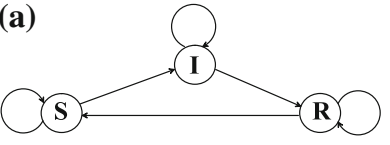

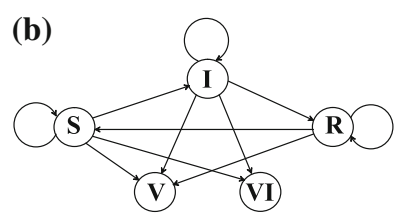

At vaccination age

(d)

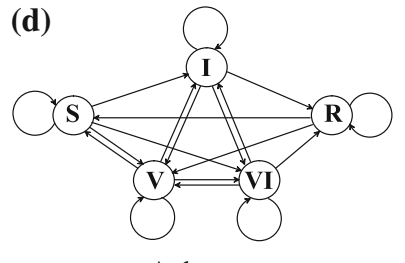

At booster age
Fig. 1 Possible transitions at different times between the five states considered in the model: susceptible of being infected (S), already infective (I), having recovered from the infection (R), vaccinated (V), and vaccinated when being infective (I). The arrows indicate the possible transitions between the five states transitions. Before vaccination occurs, only states S, I, and $\mathrm{R}$ are possible. When vaccination occurs, states $\mathrm{V}$ and VI become active. In most cases, individuals become vaccinated either from the susceptible or recovered states, but they can also come from the infective state if they clear infection the same year they are vaccinated. Individuals can become vaccinated-infective (VI) if they are vaccinated when staying infected, or if they are susceptible and get an infection the same year they are vaccinated. After vaccination, individuals can stay in the vaccinated and vaccinated-infective states, but they can also leave these states to become susceptible, infective, or recovered. Vaccinated individuals become susceptible again when the immunity provided by the vaccine vanishes, and they become infective when they lose their immunity at the same time they get infected. Finally, they can also become vaccinated-infective if they get infected when keeping the immunity provided by the vaccine, but this very particular situation can occur only if the vaccine does not provide $100 \%$ protection. Vaccinated-infective individuals become simply infective if the immunity provided by the vaccine vanishes, and they enter in the recovered state if they clear the infection at the same time. An even more complex situation occurs at the exact time a booster is administered. This complexity comes from different reasons: not all individuals will receive the booster; simultaneously to receiving the booster, an individual can also become infected, or clear an infection; a significant proportion of the population can be still protected by the vaccine. Finally, the years following a booster, transitions follow again the schema given in Fig. 1c.

Table 1 describes the main parameters of the model and gives their values as estimated for Switzerland from the literature. A more detailed description of all parameters is provided in Suris et al. (2007). There are 20 profiles of sexual activity, each of them grouping $5 \%$ of the total population of a particular age. Each profile corresponds to a different group of population and is defined as the average number of sexual partners per year. Such a large number of profiles is not mandatory, but it was the best choice given available Swiss data. For each profile and each class of age, the average number of sexual partnerships formed by year was computed from Swiss data. For instance, the first profile indicates total abstinence, whatever the age class; the ninth profile corresponds to an average of 1 sexual partner per year between ages 17 and 60 , and no partner before or after that; the last profile corresponds to an average of 2 sexual partners per year between ages 11 and 14, 9 partners between 15 and 16, 7 partners between 17 and 20, and 3 partners between 21 and 80. The parameter of sexual mixing is the probability that a sexual partnership is formed with someone belonging to a 
Table 1 Main parameters of the HPV model

\begin{tabular}{|c|c|c|}
\hline Parameter & Estimation & Main source for estimation \\
\hline Number of age classes & 9 & Specific \\
\hline Age classes & $\begin{array}{l}1-10,11-14,15-16,17-20,21- \\
30,31-45,46-60,61-80,81- \\
100\end{array}$ & Chosen in regard of available data \\
\hline Number of sexual activity profiles & 20 & Specific \\
\hline $\begin{array}{l}\text { Survival probability for individual of each age, by } \\
\text { sex }\end{array}$ & Available upon request & Swiss Statistics \\
\hline $\begin{array}{l}\text { Initial proportion of the population being infected by } \\
\text { the HPV virus, by age, sex and sexual activity } \\
\text { profile }\end{array}$ & Available upon request & $\begin{array}{l}\text { Endemic values computed from the reference } \\
\text { scenario without vaccination program }\end{array}$ \\
\hline Age at vaccination & 12 & Taira et al. (2004) \\
\hline Percentage of individuals being vaccinated, by sex & Female: $85 \%$, male: $0 \%$ & $\begin{array}{l}\text { For females: Average from the Hepatitis B } \\
\text { vaccination rate in various European } \\
\text { countries }\end{array}$ \\
\hline Age(s) of the booster(s) & $\begin{array}{l}5 \text { years after vaccination, or } 5 \text { and } \\
10 \text { years after vaccination in the } \\
\text { case of two boosters }\end{array}$ & $\begin{array}{l}\text { Our analysis is based on the assumption that } \\
\text { the period of full efficacy of the vaccine is } \\
5 \text { years, so the booster must be } \\
\text { administered at the end of this period }\end{array}$ \\
\hline Percentage of individuals receiving a booster, by sex & Female: $85 \%$, male: $0 \%$ & See vaccination rate \\
\hline $\begin{array}{l}\text { Length in years of the total immunity provided by } \\
\text { the vaccine and/or the booster(s) }\end{array}$ & Variable & $\begin{array}{l}\text { Clifford et al. (2005), Dunne and Markowitz } \\
\text { (2006) }\end{array}$ \\
\hline Catch-up procedure (yes or no) & Variable & - \\
\hline Maximal age to receive the catch-up & Variable & ACIP (2007), Saslow et al. (2007) \\
\hline $\begin{array}{l}\text { Percentage of individuals receiving the catch-up, by } \\
\text { sex }\end{array}$ & Female: $85 \%$, male: $0 \%$ & See vaccination rate \\
\hline $\begin{array}{l}\text { Proportion of vaccinated individuals losing their } \\
\text { immunity by years during the period of total } \\
\text { immunity, and then after this period }\end{array}$ & $0 \%$, then $10 \%$ & Koutsky and Harper (2006) \\
\hline $\begin{array}{l}\text { Average number of sexual partnerships formed by } \\
\text { year, for each sexual activity profile and each age } \\
\text { class }\end{array}$ & Available upon request & Narring et al. (2004); Balthasar et al. (2003) \\
\hline $\begin{array}{l}\text { Proportion of the population forming sexual } \\
\text { partnerships with individuals belonging to other } \\
\text { profiles of sexual activity }\end{array}$ & 0.8 & Specific \\
\hline $\begin{array}{l}\text { Transmission rate of the virus from one sex to } \\
\text { another }\end{array}$ & $\begin{array}{l}\text { Female to male: } 75 \% \text {, male to } \\
\text { female: } 75 \%\end{array}$ & Hugues et al. (2002) \\
\hline $\begin{array}{l}\text { Proportion of infective individuals entering in } \\
\text { remission each year }\end{array}$ & $70 \%$ & $\begin{array}{l}\text { Centers for Disease Control and Prevention } \\
\text { (2007) }\end{array}$ \\
\hline $\begin{array}{l}\text { Proportion of remission individuals becoming } \\
\text { susceptible again each year }\end{array}$ & 0.5 & Specific \\
\hline
\end{tabular}

We describe here the main parameters of the simulation model, and we provide their values as estimated for Switzerland from the literature. "Specific" indicates that the value has been chosen specifically in regard of the availability of Swiss data. "Variable" indicates that the parameter varies in function of the vaccination scenario

different sexual profile. This parameter takes a high value of 0.8 (maximum 1) reflecting the fact that with no less than 20 different profiles of sexual activity, it is likely that the majority of the sexual partnerships are formed with individuals belonging to another profile.

The vaccination coverage has been fixed to $85 \%$ (female) and $0 \%$ (male). The latter case is a consequence of the choice of not exploring male vaccination. Since no data exist at the time for HPV, the vaccination rate for females has been derived from the one for Hepatitis B. In Switzerland this rate is still low (63\% in 2006) since vaccination is not mandatory in all cantons, so we used data from other European countries (Italy: 92\%, Germany: 84\%, and Austria: 92\%) as provided by the World Health Organization (2007).

At the beginning of the simulation, an initial population is created. Each subsequent year of the simulation consists then in the following steps: 
1. The sexual mixing between the different groups of population is computed. This mixing takes into account the proportion of sexual contacts occurring between each couple of sexual activity profiles, and the average number of partnerships per age class and sexual profile.

2. A new repartition of the population between the five states is computed using a set of difference equations and the final situation of the previous year. For instance, considering the situation of Fig. 1a, we have three equations giving the number of individuals belonging to states $\mathrm{S}, \mathrm{I}$, and $\mathrm{R}$ at time $t+1$ in function of the number of individuals in these same states at time $t$ :

$$
\begin{aligned}
& \mathrm{S}_{t+1}=\mathrm{S}_{t}-\alpha \mathrm{s}_{t} \mathrm{I}_{t}+\delta \mathrm{R}_{t} \\
& \mathrm{R}_{t+1}=\mathrm{R}_{t}+\beta \mathrm{I}_{t}-\delta \mathrm{R}_{t}=(1-\delta) \mathbf{R}_{t}+\beta \mathrm{I}_{t} \\
& \mathrm{I}_{t+1}=\mathrm{I}_{t}+\alpha \mathrm{s}_{t} \mathrm{I}_{t}-\beta \mathbf{I}_{t}=\left(1+\alpha \mathrm{s}_{t}-\beta\right) \mathrm{I}_{t}
\end{aligned}
$$

The parameter $\alpha$ is the average number of infections that could be caused by an infective individual during one period. Since only susceptible individuals can become infective, the number of new infective at time $t+1$ is given by $\alpha \mathrm{s}_{t} \mathrm{I}_{t}$, where $\mathrm{s}_{t}$ is the proportion of susceptible individuals in the population at time $t$. After a certain time, infective individuals recover, and we note $\beta$ the proportion of individuals doing so each period. Finally, $\delta$ is the proportion of recovering individuals becoming susceptible again each time period. Equation 1 tells that the number of susceptible individuals at time $t+1$ is equal to the number of susceptible individuals at time $t$ minus the number of susceptible individuals infected between $t$ and $t+1$, plus the number of recovering individuals becoming susceptible again between $t$ and $t+1$. Equation 2 tells that the number of recovering individuals at time $t+1$ is equal to the number of individuals already recovering at time $t$ plus the number of infective individuals recovering between $t$ and $t+1$, minus the number of recovering individuals becoming susceptible again between $t$ and $t+1$. Finally, Eq. 3 tells that the number of infective individuals at time $t+1$ is equal to the number of infective individuals at time $t$ plus the number of individuals infected between $t$ and $t+1$, less the number of individuals having recovered between $t$ and $t+1$.

3. Results are adjusted according to the Swiss mortality table to respect the real age repartition of the population.

If a vaccination program is implemented at the beginning of the simulation, the impact of this program can be analyzed after any given number of years. The equilibrium of the epidemiological model provides the endemic repartition of the population between the five states.
Based on the recommendations of several countries, we considered the vaccination of 12 years old girls. Four scenarios were then compared regarding the efficacy of the vaccine:

1. Full efficacy of the vaccine during 5 years, no booster.

2. Full efficacy of the vaccine during 5 years, two boosters after 5 and 10 years.

3. Full efficacy of the vaccine during 10 years, no booster.

4. Lifelong full efficacy of the vaccine.

Two additional scenarios (full efficacy during 5 years, one booster after 5 years; full efficacy during 10 years, one booster after 10 years) were also considered, but we did not report results here. The first of these scenarios is always very close to the 10 years/no booster scenario. The second scenario behave like an intermediary situation between the 10 years/no booster and the 5 years/2 boosters scenarios after 15 years of vaccination, and it becomes very close to the lifelong efficacy scenario when considering the endemic situation.

Three catch-up possibilities were also studied:
A. No catch-up.
B. Catch-up up to 18 years.
C. Catch-up up to 25 years.

Our results are reported in terms of proportion of infected girls by HPV 16/18 types by age. For each type of catch-up, we compared the vaccination scenarios 15 years after the beginning of the vaccination campaign. We also report the long-term endemic situation.

The model has been developed using Matlab 7 (2004). Stata 9 (2007) has been used for additional statistical computations.

\section{Results}

Figure 2 reports the infection rate by age for females in Switzerland, both for all HPV types and for HPV 16/18 only. These are the endemic rates estimated from the model in the absence of vaccination.

The first simulation does not consider any form of catchup. Figure 3 reports the expected infection rate by age for HPV types 16/18, 15 years after the beginning of the vaccination campaign. Using a 5 -year efficacy vaccine the infection rate would remain below $1 \%$ up to age 18 , below $2 \%$ up to age 22 , and below $4 \%$ up to age 30 . By adding two boosters, the rate would remain below $1 \%$ up to age 25 and under $4 \%$ up to age 30 . A 10 -year efficacy vaccine would maintain the infection rate under $1 \%$ up to age 22 , slightly over $1 \%$ at age 25 , and below $4 \%$ at age 30 . A lifelong efficacy vaccine would follow a very similar curve. 
Fig. 2 HPV infection rate among Swiss females such as estimated by the absence of vaccination epidemiological model in the

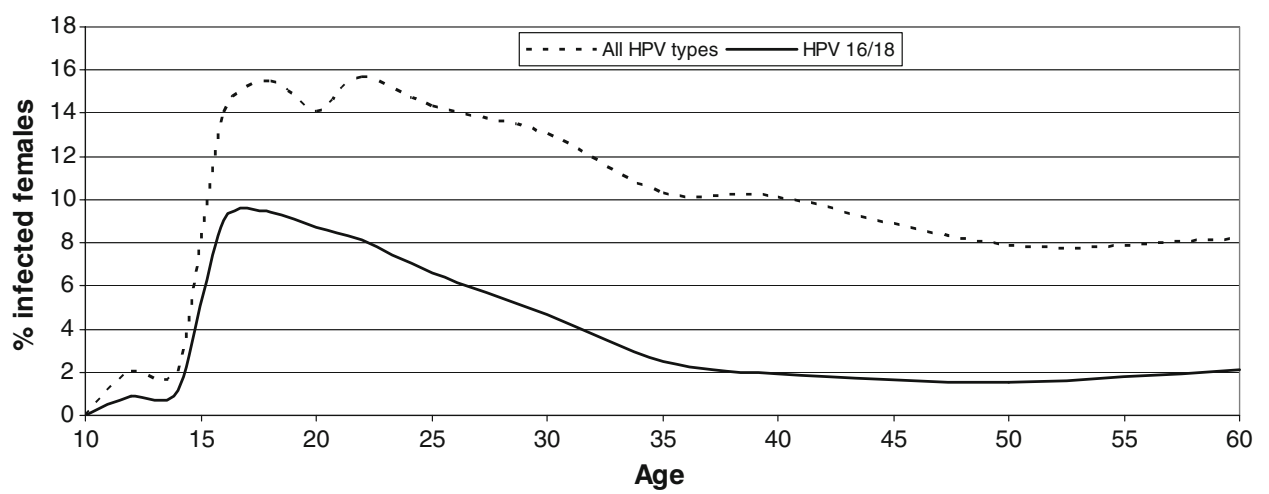

Fig. 3 Estimated HPV 16/18 infection rate for females by age. The vaccination targets 12 years old girls with $85 \%$ coverage. No catch-up. Situation 15 years after the beginning of the vaccination campaign

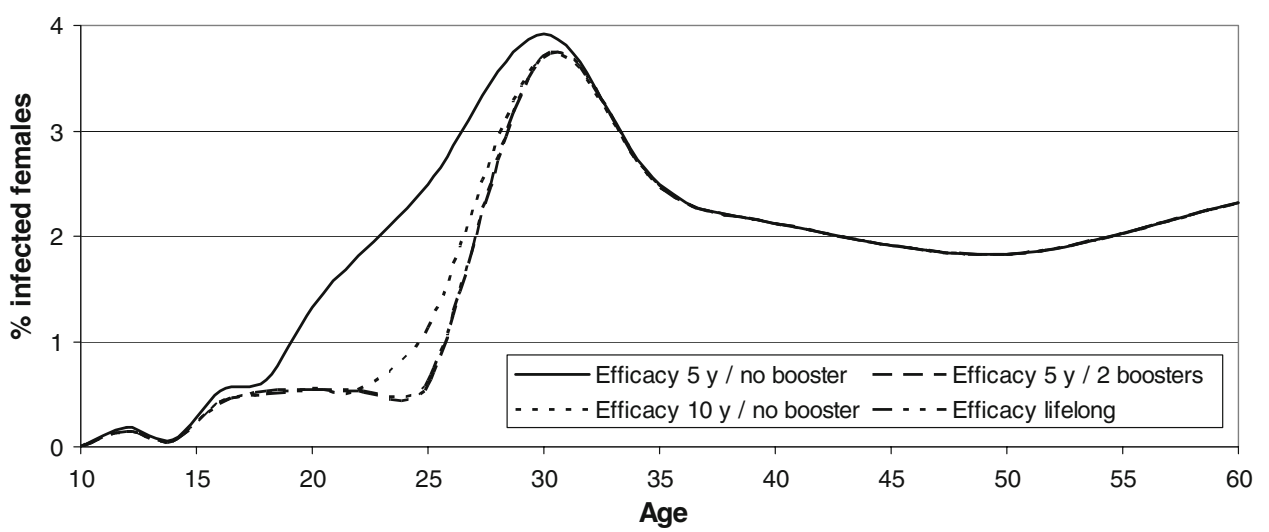

In all cases, from age 35 onwards, the rates are as low (2\% infected) as if no vaccination was administered.

The second simulation adds a catch-up up to age 18 . Figure 4 reports the expected infection rate by age for HPV types $16 / 18,15$ years after the beginning of the vaccination campaign. In this situation, a 5-year efficacy vaccine would maintain the infection rate under $1 \%$ up to age 20 and below $2.5 \%$ up to age 35 . By adding two boosters, the rate would stay below $1 \%$ up to age 30 and below $2 \%$ up to age 35. A 10 year efficacy vaccine would keep the rate below $1 \%$ up to age 25 and below $2 \%$ up to age 35 . By using a lifelong efficacy vaccine, the scenario would be very close to the 5 -years $/ 2$ boosters case. In all cases, the infection rate would be similar to non-vaccination from age 40 onwards.

The third simulation extends catch-up up to age 25 . Figure 5 reports the expected infection rate by age for HPV types 16/18, 15 years after the beginning of the vaccination campaign. A 5-year efficacy vaccine without booster would result in an infection rate below $1 \%$ up to age 20 and below $2 \%$ up to age 40 . For all other cases, the rate would be maintained below $1 \%$ up to age 37 .

The last simulation reports the endemic situation in the absence of any form of catch-up, that is the equilibrium situation which would be reached at 50 and subsequent years after the beginning of the vaccination campaign.
Fig. 4 Estimated HPV 16/18 infection rate for females by age. The vaccination targets 12 years old girls with $85 \%$ coverage. Catch-up up to 18 years. Situation 15 years after the beginning of the vaccination campaign

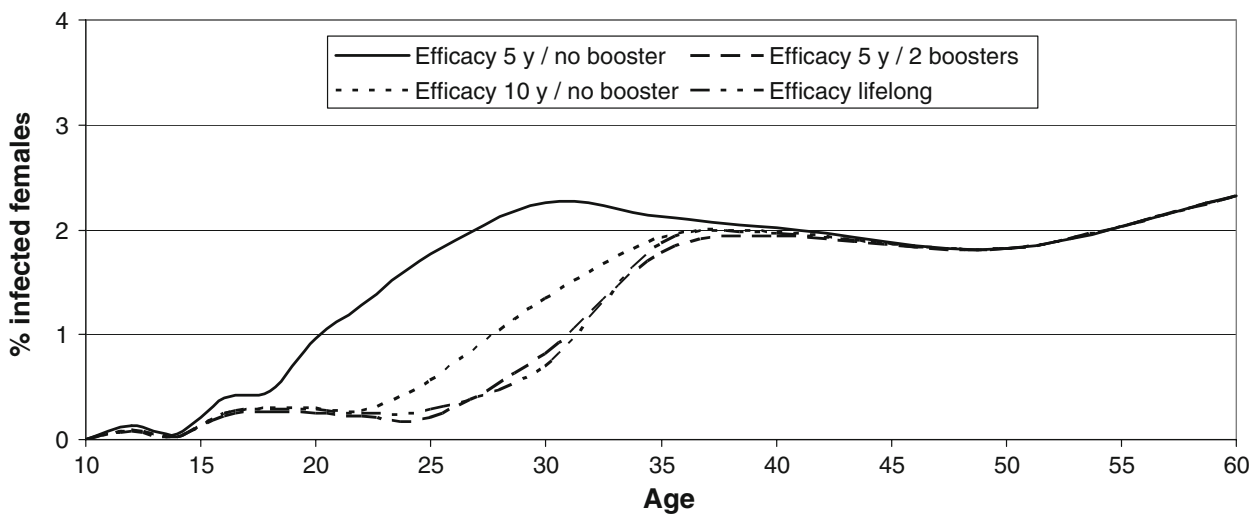


Fig. 5 Estimated HPV 16/18 infection rate for females by age. The vaccination targets 12 years old girls with $85 \%$ coverage. Catch-up up to 25 years. Situation 15 years after the beginning of the vaccination campaign

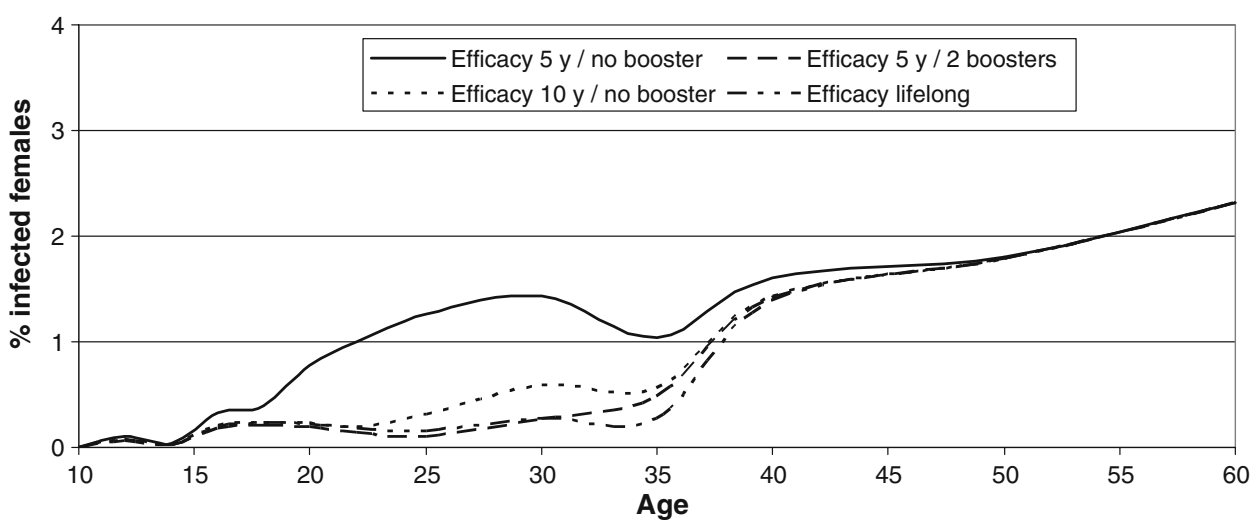

Fig. 6 Estimated HPV 16/18 infection rate for females by age. The vaccination targets 12 years old girls with $85 \%$ coverage. No catch-up. Endemic situation

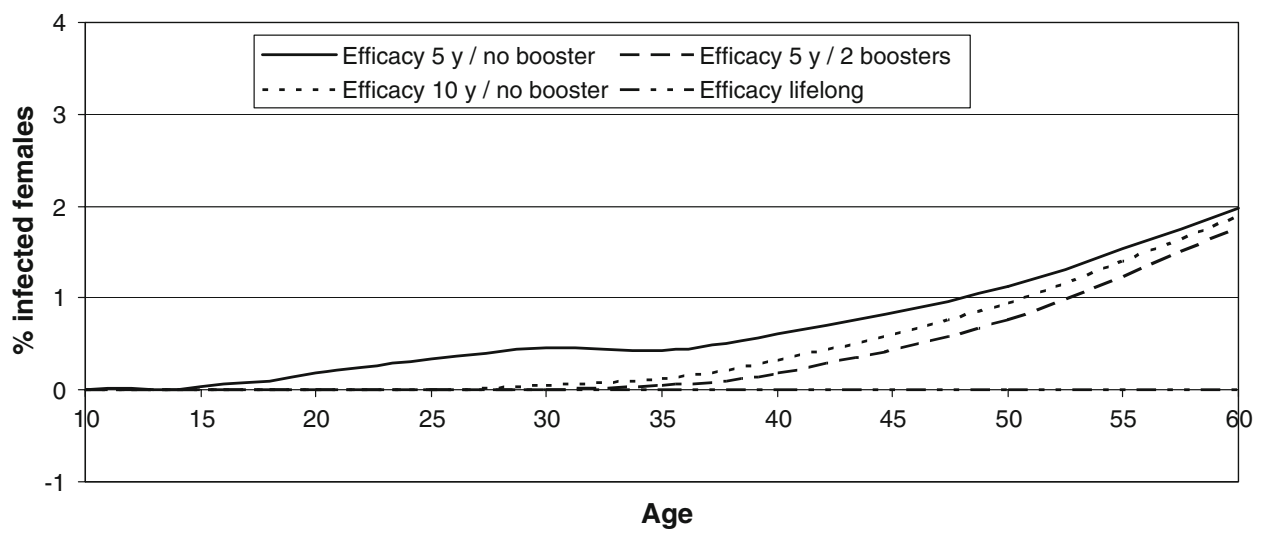

Figure 6 reports the infection rate for HPV types 16 and 18 by age. Using a 5 -year efficacy vaccine without booster, the infection rate would remain below $0.2 \%$ up to age 20 and below $0.5 \%$ up to age 35 . All other scenarios would prove even more efficient. After 35 years of age, the infection rate would slowly go up for all scenarios, except for the lifelong efficacy scenario for which the infection rate would stay null. Endemic situations with a catch-up up to 18 or 25 years are virtually identical to the endemic situation without catch-up, so we did not report the results.

\section{Discussion}

Results can be analyzed from two points of view: considering first the long-term endemic situation many years after the introduction of the vaccination, it appears clearly that whatever the duration of the protection offered by the vaccine, the administration of boosters or the introduction of a catch-up procedure, the HPV 16/18 infection rate will be dramatically decreased compared to the default situation without any vaccination. Even in the lowest vaccination scenario (5 years efficacy without booster or catch-up), the infection rate will stay below $0.5 \%$ up to 35 years of age, when the same rate would be higher than $9 \%$ by age 18 without vaccination. However, this optimistic view has to be moderated by the fact that such an endemic situation can be reached in the most favorable case only 50 years after the beginning of the vaccination campaign. In the meantime, as indicated by results after 15 years of vaccination, the infection rate will stay non-negligible, emphasizing the need for an optimal vaccination scenario.

Looking now at the mid-term impact of the vaccination, three elements are to be considered: the duration of the full efficacy of the vaccine, the use of boosters, and the catch-up procedure. At the present time, we expect that vaccine efficacy may last for decades as HPV vaccine elicit immune memory and this memory is readily reactivated by a booster dose. However, we are still unsure whether such booster doses will be needed and if so at which intervals, so we can here only speculate. Not surprisingly, the longer the full efficacy of the vaccine, the smaller the infection rate by age. The use of one or two boosters, if required to sustain the full efficacy of the vaccine, clearly improves the vaccination plan. Finally, any catch-up is better than no catch-up at all. However, our model indicates that the improvement provided by a catch-up up to age 18 compared to no catch-up at all is much more important than the improvement provided by a catch-up up to 25 compared to a catch-up up to 18 . Additional unreported results also show that a catch-up up to age 20 is similar to a catch-up up to 18. Catch-ups up 
to age 22 or 25 provide also similar results, although the later would result in better coverage and infection rates than the former. This statement is independent of the efficacy of the vaccine and of whether or not a booster is implemented.

This study presents several limitations. First of all, the model was intended for the case of Switzerland, but data for estimating the model were very scarce. In fact, the only prevalence of HPV infection we have found for Switzerland is among a small $(N=134)$ clinical sample of adolescents in Geneva (Lüdicke et al. 2001). As a result, we have been forced to rely on data from other countries, mainly the United States. Nevertheless, this fact should not influence much our results, since there are no reasons to believe that the situation regarding HPV in Switzerland differs significantly from the situation in other western developed countries. Moreover, the use of data from different countries contributes to make the model more universal.

We chose to build an epidemiological model allowing transitions from any state to any other state. It could be argued that some of these transitions should not have been included, for instance the transition from recovered to vaccinated, since the vaccine seems to be effective only for woman naive to the virus. However, this is still an area of controversy (Hildesheim and Herrero 2007). Moreover, our model tackles simultaneously HPV types 16 and 18, so we had to take into account the fact that a woman previously infected with one of these types could nevertheless obtain protection against the other one through vaccination. Finally, such transitions account for only a small number of all the transitions of the model.

The time step of the model is 1 year. This is maybe too long, since median time to clearance from HPV infections has been reported to be less than 1 year (Ho et al. 1998; Giuliano et al. 2002; Dunne and Markowitz 2006), resulting in a distortion of the results. However, the same authors also reported that clearance time was longer for the HR HPV types concerned by our study. Moreover, if our model could potentially find as still infective women which have already cleared the infection in less than 1 year, this would be counterbalanced by women found no more infective after several years by the model.

A more important limitation is the fact that there are not much data regarding the sexual behavior of Swiss. As an example, the only data that we have found for the number of sexual partners (Balthasar et al. 2003) include quite wide age ranges (17-20, 21-30, and 31-45). We had then to divide the whole modeled period into only 9 age classes. This is clearly insufficient, especially after 30 years, the consequences being a lower reliability of the exact HPV infection prevalence by age, and too abrupt changes in prevalence at the limit between age classes.
This paucity of data has not allowed us to fully calibrate our model. Given these limitations, the model should not be used to predict the exact prevalence of HPV infection age by age. However, the model correctly reproduces the relative change in prevalence due to the implementation of different vaccination scenarios, so the results are correct in regard of the objective of the present study.

The model described here focuses only on the effect of vaccination upon HPV 16 and 18 infection rates. We did not consider infection by other HPV types, what could limit the generalization of our results. We also did not consider the influence of vaccination upon screening policies, nor the impact of vaccination upon the later development of cervical cancers. The cost/benefit analysis of the vaccination is also beyond the scope of the present article. All of these questions should be addressed through additional researches.

Based on the preceding analyses, the proposals made to the Swiss Commission for Vaccination were to implement a vaccination procedure for all female adolescents between the age of 12 or 13 and to propose a catch-up procedure up to at least 18 , but preferably 25 years of age. Another proposal was to envision one (or two) boosters if needed to insure that females would be protected during the main part of the period of maximal risk, that is at least up to age 30, but ideally up to age 35 . As the maximal duration of protection of the vaccine is yet to be determined, whether no, one or two boosters would be needed remains to be defined by the long-term follow-up of vaccinated cohorts.

Other factors beyond those appraised by the epidemiological model are also to be considered when choosing an optimal vaccination plan. First of all, even if no serious side effects following vaccination have been reported yet (>15 million doses administered), we always lack information about possible mid- and long-term side effects when a new vaccine is introduced. From that point of view, there is a need to carefully monitor the effects of HPV vaccination. Given the fact that the odds for developing any neurological or autoimmune diseases increase with age (Siegrist et al. 2007), it has to be understood that to vaccinate older individuals (after 19 or 20 years of age) entails an increasing risk for lay people to falsely attribute the occurrence of illness to the vaccine. Also, the decision regarding the ideal age range for catch-up procedure must take into account cost-effectiveness calculation, which obviously differs from one epidemiological situation to another. Finally, it must be clear that vaccination cannot fully replace other prevention tools such as screening and information campaigns directed toward adolescents and young adults.

Keeping these considerations in mind, the final recommendation of the Swiss Commission for Vaccination was to vaccinate all female adolescents aged 11-14 years and 
to propose a catch-up procedure to all females aged 1519 years during a 5-year period (Swiss Commission for Vaccination 2007). The Swiss Commission for Vaccination recognized the fact that, for sexually active adolescents and young adults, the advantage of being immunized diminished as the number of previous sexual partners increased. The usefulness of HPV vaccination, particularly from age 20 , will thus have to be determined on an individual basis.

Acknowledgments This article is mostly based on a report (Suris et al. 2007) following a request of the Swiss Commission for Vaccination to the Groupe de Recherche sur la Santé des Adolescents (GRSA) to perform a modeling of the HPV seroconversion among Swiss females after introducing the HPV vaccine. We thank ClaireAnne Siegrist for her very careful reading of the paper. This research has been financed by GlaxoSmithKline AG, Switzerland. GlaxoSmithKline had no role in the design and conduct of the study, in the collection and the interpretation of the data, or in the preparation of the manuscript.

\section{References}

ACIP Provisional Recommendations for the Use of Quadrivalent HPV Vaccine (2007) http://www.cdc.gov/Nip/recs/provisional_ recs/hpv.pdf. Accessed 28 Feb 2007

Anderson RM (1982) Population dynamics of infectious diseases. Theory and applications. Chapman and Hall, New York

Aral SO, Hughes JP, Stoner B, Whittington W, Handsfield HH, Anderson RM, Holmes KK (1999) Sexual mixing patterns in the spread of gonococcal and chlamydial infections. Am J Public Health 89:825-833

Ault KA (2007) Long-term efficacy of human papillomavirus vaccination. Gynecol Oncol 107:S27-S30

Balthasar H, Spencer B, Addor V (2003) Indicateurs de santé sexuelle et reproductive en Suisse: Module pour le site de l'Observatoire de la santé. Lausanne: Institut universitaire de médecine sociale et préventive. http://www.obsan.admin.ch/bfs/obsan/de/index/ 05/06.Document.105407.pdf. Accessed 15 Aug 2009

Barnabas RV, Laukkanen P, Koskela P, Kontula O, Lehtinen M, Garnett GP (2006) Epidemiology of HPV 16 and cervical cancer in Finland and the potential impact of vaccination: mathematical modelling analyses. PLoS Med 3:e138

Bosch X, Harper D (2006) Prevention strategies of cervical cancer in the HPV vaccine era. Gynecol Oncol 103:21-24

Bosch FX, Lorincz A, Muñoz N, Meijer CJLM, Shah KV (2002) The causal relation between human papillomavirus and cervical cancer. J Clin Pathol 55:244-265

Brown DR, Shew ML, Qadradi B, Neptune N, Vargas M, Tu W, Juliar BE, Breen TE, Fortenberry JD (2005) A longitudinal study of genital human papillomavirus infection in a cohort of closely followed adolescent women. J Infect Dis 191:182-192

Burchell AN, Winer RL, de Sanjosé S, Franco EL (2006) Epidemiology and transmission dynamics of genital HPV infection. Vaccine 24(suppl 3):S52-S61

Centers for Disease Control and Prevention (2007) Human papillomavirus: HPV information for clinicians. http://www.cdc. gov/std/HPV/common-clinicians/ClinicianBro-br.pdf. Accessed 6 Nov 2007

Clifford GM, Gallus S, Herrero R, Muñoz N, Snijders PJF, Vaccarella S, Anh PTH, Ferreccio C, Hieu NT, Matos E, Molano M, Rajkumar R, Ronco G, de Sanjosé S, Shin HR, Sukvirach S, Thomas JO, Tunsakul S, Meijer CJLM, Franceschi S, The IARC
HPV Prevalence Surveys Study Group (2005) Worldwide distribution of human papillomavirus types in cytologically normal women in the International Agency for Research on Cancer HPV prevalence surveys: a pooled analysis. Lancet 366:991-998

Corley C (2006) Modeling the Impact and Intervention of a sexually transmitted disease: human papilloma virus. Department of Computer Science and Engineering, University of North Texas, USA

Daley DJ, Gani J (2001) Epidemic modelling: an introduction. University Press, Cambridge

Dunne EF, Markowitz LE (2006) Genital human papillomavirus infection. Clin Infect Dis 43:624-629

Dunne EF, Unger ER, Sternberg M, McQuillan G, Swan DC, Patel SS, Markowitz LE (2007) Prevalence of HPV infection among females in the United States. JAMA 297:813-819

French KM, Barnabas RV, Lehtinen M, Kontula O, Pukkala E, Dillner J, Garnett GP (2007) Strategies for the introduction of human papillomavirus vaccination: modelling the optimum ageand sex-specific pattern of vaccination in Finland. Br J Cancer 96:514-518

Garnett GP (2002) An introduction to mathematical models in sexually transmitted disease epidemiology. Sex Transm Infect 78:7-12

Giuliano AR, Harris R, Sedjo RL, Baldwin S, Roe D, Papenfuss MR, Abrahamsen M, Inserra P, Olvera S, Hatch K (2002) Incidence, prevalence, and clearance of type-specific human papillomavirus infections: The Young Women's Health Study. J Infect Dis 186:462-469

Hildesheim A, Herrero R (2007) Human papillomavirus vaccine should be given before sexual debut for maximum benefit. J Infect Dis 196:1431-1432

Ho GYF, Bierman R, Beardsley L, Chang CJ, Burk RD (1998) Natural history of cervicovaginal papillomavirus infection in young women. N Engl J Med 338:423-428

Hugues JP, Garnett GP, Koutsky L (2002) The theoretical populationlevel impact of a prophylactic human papilloma virus vaccine. Epidemiology 13:631-639

IARC Monograph Working Group (2007) IARC monographs on the evaluation of carcinogenic risks to humans, vol 9. In: Cogliano V, Baan R, Straif K et al (eds) Human papillomaviruses. IARC Press, Lyon

Insinga RP, Dasbach EJ, Elbasha EH, Puig A, Reynales-Shigematsu LM (2007) Cost-effectiveness of quadrivalent human papillomavirus (HPV) vaccination in Mexico: a transmission dynamic model-based evaluation. Vaccine 26:128-139

Kahn JA, Rosenthal SL, Succop PA, Ho GY, Burk RD (2002) Mediators of the association between age of first sexual intercourse and subsequent human papillomavirus infection. Pediatrics 109:E5

Kermack WO, McKendrick AG (1927) A contribution to the mathematical theory of epidemics. Proc R Soc Lond A 115:700-721

Kjaer SK, Chackerian B, van den Brule AJC, Svare EI, Paull G, Walbomers JMM, Schiller JT, Bock JE, Sherman ME, Lowy DR, Meijer CLM (2001) High-risk human papillomavirus is sexually transmitted: evidence from a follow-up study of virgins starting sexual activity (intercourse). Cancer Epidemiol Biomarkers Prev 10:101-106

Koutsky LA, Harper DM (2006) Current findings from prophylactic HPV vaccine trials. Vaccine 24(suppl 3):S114-S121

Kuendig H, Kuntsche EN, Delgrande Jordan M, Schmid H (2003) Enquête sur les comportements de santé des élèves de 1 à 16 ans. Une statistique descriptive des données nationales de 2002. ISPA, Lausanne

Lowy DR, Schiller JT (2006) Prophylactic human papillomavirus vaccines. J Clin Invest 116:1167-1173 
Lüdicke F, Stalberg A, Vassilakos P, Major AL, Campana A (2001) High- and intermediate-risk human papillomavirus infection in sexually active adolescent females. J Pediatr Adolesc Gynecol 14:171-174

Manhart LE, Holmes KK, Koutsky LA, Wood TR, Kenney DL, Feng Q, Kiviat NB (2006) Human papillomavirus infection among sexually active young women in the United States: implications for developing a vaccination strategy. Sex Transm Dis 33:502508

Matlab Version 7.0 (2004) The MathWorks Inc., Natick, Massachusetts

Moscicki AB, Hills N, Shiboski S, Powell K, Jay N, Hanson E, Miller S, Clayton S, Farhat S, Broering J, Darragh T, Palefsky J (2001) Risks for incident human papillomavirus infection and low-grade squamous intraepithelial lesion development in young females. JAMA 285:2995-3002

Narring F, Tschumper A, Inderwildi Bonivento L, Jeannin A, Addor V, Bütikofer A, Suris JC, Diserens C, Alsaker F, Michaud PA (2004) Santé et styles de vie des adolescents âgés de 16 à 20 ans en Suisse (2002). Institut Universitaire de Médecine Sociale et Préventive, Lausanne. http://www.iumsp.ch/Publications/pdf/ RdS95a_fr.pdf. Accessed 15 Aug 2009

Peto J, Gilham C, Deacon J, Taylor C, Evans C, Binns W, Haywood M, Elanko N, Coleman D, Yule R, Desai M (2004) Cervical HPV infection and neoplasia in a large population-based prospective study: the Manchester cohort. Br J Cancer 91:942953

Saslow D, Castle PE, Cox JT et al (2007) American cancer society guideline for human papillomavirus (HPV) vaccine use to prevent cervical cancer and its precursors. CA Cancer J Clin 57:7-28

Sellors JW, Karwalajtys TL, Kaczorowski J, Mahony JB, Lytwyn A, Chong S, Sparrow J, Lorincz A (2003) Incidence, clearance and predictors of human papillomavirus infection in women. CMAJ 168:421-425

Siegrist CA, Lewis EM, Eskola J, Evans SJ, Black SB (2007) Human papilloma virus immunization in adolescent and young adults: a cohort study to illustrate what events might be mistaken for adverse reactions. Pediatr Infect Dis J 26:979-984

Stata Statistical Software Version 9.2 (2007) Stata Corporation, College Station, Texas

Suris JC, Berchtold A, Nardelli D, Michaud PA (2007) Modeling of HPV seroconversion in adolescent girls in Switzerland: Centre Hospitalier Universitaire Vaudois. http://my.unil.ch/serval/ document/BIB_10313CEAA18D.pdf. Accessed 1 Sep 2009

Swiss Commission for Vaccination (2007) Plan de vaccination Suisse 2007. www.snm.ch/prive/specialites/pediatrie/planvaccin_ssp. pdf. Accessed 28 Nov 2007

Taira AV, Neukermans CP, Sanders GD (2004) Evaluating human papillomavirus vaccination programs. Emerg Infect Dis 10:1915-1923

Tarkowski TA, Koumans EH, Sawyer M, Pierce A, Black CM, Papp JR, Markowitz L, Unger ER (2004) Epidemiology of human papillomavirus infection and abnormal cytologic test results in an urban adolescent population. J Infect Dis 189:46-50

Wellings K, Collumbien M, Slaymaker E, Singh S, Hodges Z, Patel D, Bajos N (2006) Sexual behaviour in context: a global perspective. Lancet 368:1706-1728

Wiley D, Masongsong E (2006) Human papillomavirus: the burden of infection. Obstet Gynecol Surv 61(6 suppl 1):S3-S14

Winer RL, Lee SK, Hughes JP, Adam DE, Kiviat NB, Koutsky LA (2003) Genital human papillomavirus infection: incidence and risk factors in a cohort of female university students. Am J Epidemiol 157:218-226

Winer RL, Hughes JP, Feng Q, O'Reilly S, Kiviat NB, Holmes KK, Koutsky LA (2006) Condom use and the risk of genital human papillomavirus infection in young women. $\mathrm{N}$ Engl $\mathrm{J}$ Med 354:2645-2654

World Health Organization (2007) Third dose of hepatitis B vaccine. Reported estimates of HepB3 coverage. http://www.who. int/immunization_monitoring/en/globalsummary/timeseries/ tscoveragehepb3.htm. Accessed 1 Feb 2007 